\title{
KOMPETENSI PROFESIONAL GURU SMA KALAM KUDUS MEDAN
}

\author{
Charles Fransiscus Ambarita
}

Surel : charles.ambarita@yahoo.com

\begin{abstract}
This research aims to find the relationship between the professional competence of teachers and work discipline. Sample of research is 5 teachers of Kalam Kudus School Medan. Data collection techniques by questionnaire and documentation method. Based on the data, from 5 respondents who get below average score are 1 person, while those who get score between top and bottom average are 3 people and who get above average is 1 person. This means that high school teachers of Kalam Kudus has known and implement the teacher professionals in teaching and learning process in class and Kalam Kudus School Medan.
\end{abstract}

Key Words: Professional Ability and Work Discipline

\begin{abstract}
ABSTRAK
Penelitian ini bertujuan untuk mencari hubungan antara kompetensi profesional guru dengan displin kerja. Sampel penelitian adalah 5 orang guru SMA Kalam Kudus Medan. Teknik pengumpulan data dilakukan dengan angket dan metode dokumentasi. Berdasarkan data yang diperoleh, 5 orang responden yang mendapatkan skor dibawah rata-rata sebanyak 1 orang, sedangkan yang mendapatkan skor di antara atas dan bawah rata-rata sebanyak 3 orang serta yang mendapatkan di atas rata-rata ada 1 orang. Hal ini berarti bahwa guru sekolah SMA Kalam Kudus telah menjalankan dan mengimpelementasikan profesional guru terhadap disiplin kerja guru dalam proses belajar mengajar di kelas dan sekolah Kalam Kudus Medan.
\end{abstract}

Kata Kunci: Kemampuan Profesional dan Disiplin Kerja

\section{PENDAHULUAN}

Guru merupakan tenaga kependidikan yang memiliki tugas untuk mendidik, mengajar, serta mengarahkan peserta didik agar memiliki daya saing global yang semakin ketat dengan bangsa lain. Oleh karena guru posisi dan kedudukan guru sebagai tenaga professional sangatlah krusial dalam mewujudkan visi dan misi penyelenggaraan pendidikan pada satuan pendidikan tempat dimana guru tersebut mengajar.
Undang-undang guru dan dosen Nomor 14 Tahun 2005 dan Peraturan Pemerintah Nomor 19 Tahun 2005 menyatakan bahwa kompetensi guru meliputi kompetensi kepribadian, kompetensi pedagogik, komptensi profesional, dan kompetensi sosial. Semua komptensi tersebut harus dimiliki guru dalam melaksanakan kegiatan belajar mengajar di sekolah dan merupakan tanggung jawab yang harus dimiliki guru dalam menjalankan profesinya. 

Guru yang bermutu adalah guru yang profesional dalam pekerjaannya karena guru harus senantiasa meningkatkan kualitas dengan pengembangan dirinya. Guru profesional adalah guru yang mengedepankan mutu dan kualitas layanan dan produknya, dimana pelayanan yang diberikan guru harus memenuhi standarisasi kebutuhan masyarakat dan stakeholders. Oleh karena itu, guru harus mampu menguasai kompetensi tersebut sehingga peserta didik dapat dengan mudah menyerap ilmu yang disampaikan.

Profesional guru dikatakan baik jika guru melakukan unsurunsur yang terdiri dari kesetiaan dan komitmen yang tinggi, menguasai dan mengembangkan bahan ajar, kedisiplinan dalam mengajar dan tugas lainnya, kreativitas dalam pelaksanaan pengajaran, kerjasama dengan semua warga sekolah, kepemimpinan yang menjadi panutan siswa, kepribadian yang baik, jujur, dan objektif dalam menilai dan membimbing siswa, serta bertanggung jawab terhadap tugasnya.

Berdasarkan pengamatan yang dilakukan bahwa kompetensi profesioanal guru di SMA Kalam Kudus Medan masih rendah. Hal ini dilihat dari rendahnya kemampuan guru mengembangkan media pembelajaran dan silabus, disiplin guru masih rendah, tingkat pendidikan juga masih banyak yang tidak memenuhi syarat. Tentu semua masalah tersebut dapat menghambat dalam ketercapaian hasil belajar peserta didik dan diperlukan upaya yang optimal agar kompetensi profesional guru dapat ditingkatkan.

\section{METODE PENELITIAN}

Jenis penelitian ini merupakan penelitian korelasional. Darmadi (2011:165) menjelaskan bahwa penelitian korelasi adalah suatu penelitian yan berkaitan dengan pengumpulan data untuk menentukan ada tidaknya hubunganm seberapa jauh hubungan antara dua variabel atau lebih. Adapun pendekatan penelitian yang digunakan dalam penelitian ini adalah pendekatan kualitatif yang mendeskripsikan dan menganalisis fenomena, aktivitas sosial, sikap, kepercayaan, persepsi, sehingga mendapatkan kesimpulan yang dapat digeneralisasikan.

Subyek dalam penelitian ini dilakukan pada 5 orang guru. Penelitian dilakukan di sekolah Kalam Kudus Medan, Kecamatan Medan Helvetia Kotamadya Medan. Penelitian ini dilaksanakan pada bulan Mei 2017.Populasi dalam penelitian ini berjumlah 16 orang guru SMA Kalam Kudus Medan yang mengajar di tingkat SMA. Sugiono (2008:115) mengatakan bahwa populasi adalah wilayah generalisasi yang terdiri atas obyek atau subyek yang mempunyai kualitas dan karakteristik tertentu yang ditetapkan oleh peneliti untuk dipelajari dan kemudian ditarik kesimpulannya. Sampel penelitian berjumlah 5 orang guru SMA Kalam 
Charles Fransiscus Ambarita : Kompetensi Profe ....

Kudus Medan. Teknik pengambilan sampel dalam penelitian ini menggunakan teknik sampling. Untuk memperoleh data sesuai dengan tujuan penelitian, digunakan teknik pengumpulan data yaitu metode angket (kuesinoner) dan metode dokumentasi.

\section{HASIL PENELITIAN DAN} PEMBAHASAN

Jumlah guru yang mengajar di sekolah SMA Kalam Kudus Medan berjumlah 16 orang. Dalam pelaksanaan penelitian ini, 8 orang guru tidak dapat menjadi responden dengan alasan bahwa guru-guru tersebut sedang melaksanakan pengawasan di sekolah lain, 3 orang guru sedang dalam masa cuti, sehingga guru kelas tingkat SMA yang menjadi responden sebanyak 5 orang.

Berdasarkan hasil penelitian yang telah dilakukan, diperoleh hasil sebagai berikut:

a. Profesional guru dalam pembelajaran kode etik guru

\begin{tabular}{|l|l|l|l|}
\hline $\begin{array}{l}\text { NO } \\
\text { SOAL }\end{array}$ & $\begin{array}{l}\text { ALTERNATIF } \\
\text { JAWABAN }\end{array}$ & F & $\%$ \\
\hline 1 & Ya & 4 & $80 \%$ \\
\hline & Kadang-kadang & 1 & $20 \%$ \\
\hline & Tidak Pernah & 0 & $0 \%$ \\
\hline & Jumlah & 5 & $100 \%$ \\
\hline
\end{tabular}

b. Profesional guru dalam penguasaan bahan pengayaan

\begin{tabular}{|l|l|l|l|}
\hline $\begin{array}{l}\text { NO } \\
\text { SOAL }\end{array}$ & $\begin{array}{l}\text { ALTERNATIF } \\
\text { JAWABAN }\end{array}$ & F & $\%$ \\
\hline 2 & Ya & 5 & $100 \%$ \\
\hline & Kadang-kadang & 0 & $0 \%$ \\
\hline & Tidak Pernah & 0 & $0 \%$ \\
\hline & Jumlah & 5 & $100 \%$ \\
\hline
\end{tabular}

c. Profesional guru dalam mengajar menggunakan silabus dan RPP

\begin{tabular}{|l|l|l|l|}
\hline $\begin{array}{l}\text { NO } \\
\text { SOAL }\end{array}$ & $\begin{array}{l}\text { ALTERNATIF } \\
\text { JAWABAN }\end{array}$ & F & $\%$ \\
\hline 3 & Ya & 5 & $100 \%$ \\
\hline & Kadang-kadang & 0 & $0 \%$ \\
\hline & Tidak Pernah & 0 & $0 \%$ \\
\hline & Jumlah & 5 & $100 \%$ \\
\hline
\end{tabular}

d. Profesional guru dalam menjabarkan kompetensi dasar

\begin{tabular}{|l|l|l|l|}
\hline $\begin{array}{l}\text { NO } \\
\text { SOAL }\end{array}$ & $\begin{array}{l}\text { ALTERNATIF } \\
\text { JAWABAN }\end{array}$ & F & \% \\
\hline 4 & Ya & 3 & $60 \%$ \\
\hline & Kadang-kadang & 2 & $40 \%$ \\
\hline & Tidak Pernah & 0 & $0 \%$ \\
\hline & Jumlah & 5 & $100 \%$ \\
\hline
\end{tabular}

e. Profesional guru dalam mengajar merumuskan tujuan dari materi pembelajaran

\begin{tabular}{|l|l|l|l|}
\hline $\begin{array}{l}\text { NO } \\
\text { SOAL }\end{array}$ & $\begin{array}{l}\text { ALTERNATIF } \\
\text { JAWABAN }\end{array}$ & F & $\%$ \\
\hline 5 & Ya & 4 & $80 \%$ \\
\hline & Kadang-kadang & 1 & $20 \%$ \\
\hline & Tidak Pernah & 0 & $0 \%$ \\
\hline & Jumlah & 5 & $100 \%$ \\
\hline
\end{tabular}


SEJ VOLUME 7 NO. 2 JUNI 2017

f. Profesional guru dalam memilih dan menggunakan model pembelajaran

\begin{tabular}{|l|l|l|l|}
\hline $\begin{array}{l}\text { NO } \\
\text { SOAL }\end{array}$ & $\begin{array}{l}\text { ALTERNATIF } \\
\text { JAWABAN }\end{array}$ & F & $\%$ \\
\hline 5 & Ya & 4 & $80 \%$ \\
\hline & Kadang-kadang & 1 & $20 \%$ \\
\hline & Tidak Pernah & 0 & $0 \%$ \\
\hline & Jumlah & 5 & $100 \%$ \\
\hline
\end{tabular}

g. Profesional guru dalam penguasaan keterkaitan materi kepada siswa

\begin{tabular}{|l|l|l|l|}
\hline $\begin{array}{l}\text { NO } \\
\text { SOAL }\end{array}$ & $\begin{array}{l}\text { ALTERNATIF } \\
\text { JAWABAN }\end{array}$ & F & $\%$ \\
\hline 7 & Ya & 4 & $80 \%$ \\
\hline & Kadang-kadang & 0 & $0 \%$ \\
\hline & Tidak Pernah & 1 & $20 \%$ \\
\hline & Jumlah & 5 & $100 \%$ \\
\hline
\end{tabular}

h. Profesional guru dalam penguasaan manfaat dari pemaparan materi

\begin{tabular}{|l|l|l|l|}
\hline $\begin{array}{l}\text { NO } \\
\text { SOAL }\end{array}$ & $\begin{array}{l}\text { ALTERNATIF } \\
\text { JAWABAN }\end{array}$ & F & $\%$ \\
\hline 8 & Ya & 4 & $80 \%$ \\
\hline & Kadang-kadang & 0 & $0 \%$ \\
\hline & Tidak Pernah & 1 & $20 \%$ \\
\hline & Jumlah & 5 & $100 \%$ \\
\hline
\end{tabular}

i. Profesional guru dalam menyesuaikan tingkat kemampuan peserta didik

\begin{tabular}{|l|l|l|l|}
\hline $\begin{array}{l}\text { NO } \\
\text { SOAL }\end{array}$ & $\begin{array}{l}\text { ALTERNATIF } \\
\text { JAWABAN }\end{array}$ & F & $\%$ \\
\hline 9 & Ya & 3 & $60 \%$ \\
\hline & Kadang-kadang & 2 & $40 \%$ \\
\hline
\end{tabular}


Charles Fransiscus Ambarita : Kompetensi Profe ....

m. Profesional guru dalam membuat media pembelajaran

\begin{tabular}{|l|l|l|l|}
\hline $\begin{array}{l}\text { NO } \\
\text { SOAL }\end{array}$ & $\begin{array}{l}\text { ALTERNATIF } \\
\text { JAWABAN }\end{array}$ & F & $\%$ \\
\hline 13 & Ya & 3 & $60 \%$ \\
\hline & Kadang-kadang & 2 & $40 \%$ \\
\hline & Tidak Pernah & 0 & $0 \%$ \\
\hline & Jumlah & 5 & $100 \%$ \\
\hline
\end{tabular}

n. Profesional guru dalam menggunakan laboratorium sebagai media pembelajaran untuk mengembangkan potensi siswa

\begin{tabular}{|l|l|l|l|}
\hline $\begin{array}{l}\text { NO } \\
\text { SOAL }\end{array}$ & $\begin{array}{l}\text { ALTERNATIF } \\
\text { JAWABAN }\end{array}$ & F & $\%$ \\
\hline 14 & Ya & 0 & $0 \%$ \\
\hline & Kadang-kadang & 1 & $20 \%$ \\
\hline & Tidak Pernah & 4 & $80 \%$ \\
\hline & Jumlah & 5 & $100 \%$ \\
\hline
\end{tabular}

o. Profesional guru dalam menggunakan buku-buku dalam perpustakaan untuk menambah wawasan siswa

\begin{tabular}{|l|l|l|l|}
\hline $\begin{array}{l}\text { NO } \\
\text { SOAL }\end{array}$ & $\begin{array}{l}\text { ALTERNATIF } \\
\text { JAWABAN }\end{array}$ & F & $\%$ \\
\hline 15 & Ya & 4 & $80 \%$ \\
\hline & Kadang-kadang & 1 & $20 \%$ \\
\hline & Tidak Pernah & 0 & $0 \%$ \\
\hline & Jumlah & 5 & $100 \%$ \\
\hline
\end{tabular}

Berdasarkan pada hasil perhitungan dapat diperoleh data kinerja guru dengan skor tertinggi 42 dan skor terendah 38. Mean atau nilai rata-rata adalah 36,6. Dan simpangan baku 0,895. Rincian data sebagai berikut:

\section{Distribusi Frekuensi Profesional}

Guru

\begin{tabular}{|l|l|l|l|l|}
\hline NO & $\begin{array}{l}\text { KELAS } \\
\text { INTERVAL }\end{array}$ & F & Fkb & X \\
\hline 1 & $45-43$ & 0 & 5 & 0 \\
\hline 2 & $43-41$ & 1 & 5 & 42 \\
\hline 3 & $41-39$ & 3 & 4 & 40 \\
\hline 4 & $39-37$ & 1 & 1 & 38 \\
\hline 5 & $37-35$ & 0 & 0 & 0 \\
\hline & TOTAL & 5 & 15 & 120 \\
\hline
\end{tabular}

\section{Pembahasan}

Berdasarkan penyajian data di atas, dari 5 orang responden yang mendapatkan skor dibawah rata-rata sebanyak 1 orang, sedangkan yang mendapatkan skor di antara atas dan bawah rata-rata sebanyak 3 orang serta yang mendapatkan di atas ratarata ada 1 orang.

Dapat disimpulkan bahwa nilai rata-rata tentang profesional guru dikategorikan pada rata-rata cukup baik, artinya bahwa guru sekolah SMA Kalam Kudus telah menjalankan dan mengimpelementasikan profesional guru terhadap disiplin kerja guru dalam proses belajar mengajar di kelas dan sekolah Kalam Kudus Medan.

\section{SIMPULAN}

Berdasarkan hasil penelitian yang dilakukan di SMA Kalam Kudus Medan, dimensi profesional guru meliputi perencanaan 
SEJ VOLUME 7 NO. 2 JUNI 2017

pembelajaran,

pembelajaran,

pelaksanaan

evaluasi

pembelajaran, dan disiplin tugas

berada pada kategori cukup baik

dengan skor 96,6. Hal ini membuktikan bahwa guru sekolah

SMA Kalam Kudus Medan menjalankan tanggung jawab profesinya dengan cukup baik sesuai dengan tuntutan profesional guru.

\section{DAFTAR RUJUKAN}

Darmadi, Hamid. 2011.Metode Penelitian Pendidikan.

Bandung: Alfabeta .

Peraturan Pemerintah Nomor 19 Tahun 2005 Tentang Standar Nasional Pendidikan. Jakarta: Depdiknas.

Sugiono. 2008. Metode Penelitian Kuantitatif Kualitatif dan $R \& D$. Bandung: Alfabeta

Undang-Undang Nomor 14 Tahun 2005 Tentang Guru dan Dosen. Jakarta: Depdiknas. 